\title{
The lifespan development of cognate guessing skills in an unknown related language
}

\author{
Jan Vanhove* and Raphael Berthele
}

\begin{abstract}
This study investigates the lifespan development of the ability to correctly guess the meaning of foreign-language words with known translation-equivalent cognates. It also aims to identify the cognitive and linguistic factors driving this development. To this end, 159 German-speaking Swiss participants aged 10 to 86 were asked to translate 45 written and 45 spoken isolated Swedish words with German, English or French cognates. In addition, they were administered an English language test, a German vocabulary test as well as fluid intelligence and working memory tests. Cognate guessing skills were found to improve into young adulthood, but whereas they show additional increases in the written modality throughout adulthood, they start to decrease from age 50 onwards for spoken stimuli. Congruently with these findings, L1 vocabulary knowledge is a stronger predictor of written cognate guessing success, whereas fluid intelligence is the most important predictor in the spoken modality. Raw data and computer code used for the analyses are freely available online.
\end{abstract}

Keywords: cognates, inferencing, lifespan development, receptive multilingualism, transfer

\section{Introduction}

This paper investigates the lifespan development of a key asset to the foreign language learner: the ability to spot cross-linguistic similarities in the lexicon. Cross-linguistic similarities in general are helpful in foreign language learning(e.g. Ringbom 1987, 2007), but in this paper we are interested specifically in the cross-linguistic similarities offered by cognates. Cognates are genealogically related words with similar meanings in different languages, e.g. the German-English word pairs Schule 'school', tanzen 'to dance', and Familie 'family'. Such cognate relationships are useful in

* Corresponding author: Jan Vanhove: Department of Multilingualism, University of Fribourg,Rue de Rome 1, 1700 Fribourg, Switzerland. E-mail: jan.vanhove@unifr.ch

Raphael Berthele: Department of Multilingualism, University of Fribourg, Rue de Rome 1, 1700Fribourg, Switzerland. E-mail: raphael.berthele@unifr.ch 
foreign language learning and essential in receptive multilingualism (Section 1.1). However, it is not yet clear how the ability to recognise and make use of these interlingual links develops across the lifespan (Section 1.2) and what cognitive and linguistic factors drive this development (Section 2). To address this issue, we asked 159 Swiss native speakers of German aged 10 to 86 years to guess the meaning of isolated words in an unknown foreign language (Lx), viz. Swedish, using their knowledge of German, English and French.

\subsection{Cognates in language learning and receptive multilingualism}

Due to their genealogical link, cognates often show some formal overlap that foreign language learners can make use of. For instance, cognateness makes it easier to memorise foreign language vocabulary that has been explicitly imparted (De Groot and Keijzer 2000; Lotto and De Groot 1998). Furthermore, cognate relationships can grant learners access to a reservoir of potential target language vocabulary without explicit instruction - receptively at first but perhaps even productively later on (e.g. Bravo et al. 2007; Dressler et al. 2011; Lubliner and Hiebert 2011). Additionally, pervasive cross-linguistic similarities between closely related languages can render one language largely intelligible to speakers of the other. The phenomenon of being able to (partly) understand language varieties that one has not previously learnt is referred to as receptive multilingualism and can be observed in Scandinavia (e.g. Delsing and Lundin Åkesson 2005; Haugen 1966), between Portuguese and Spanish (e.g. Jensen 1989) and between Dutch and German (Gooskens et al. 2011; Ház 2005), to mention but a few examples. Capitalising on cognate relationships is consequently often considered an essential part of efficient language learning (e.g. Carton 1971; Haastrup 1991; Meißner 1999; Rubin 1975) and a sine qua non for receptive multilingualism (Möller and Zeevaert 2010; Van Heuven 2008).

\subsection{Positive language transfer and age}

When language users or learners make use cross-linguistic similarities when processing the target language, this constitutes a case of (positive) cross-linguistic influence or language transfer (Odlin 1989: 27) or what Carton (1971) dubbed interlingual inferencing. But despite large bodies of research on language transfer or inferencing processes on the one hand (see e.g. Odlin 1989; Jarvis and Pavlenko 2008; Ringbom 2007) and on the age factor in language learning and multilingualism on the other (see e.g. Muñoz 2006; Singleton and Ryan 2004), hardly any research has systematically investigated how the ability to put cross-linguistic similarities to good use develops across the lifespan. To our knowledge, the first study to target this development was conducted by Cenoz (2001), who investigated how the transfer tendencies of 90 Basque-Spanish bilingual 
learners of English aged 7 to 14 changed as a function of their age. The main finding was that older learners were more likely to transfer Spanish (as opposed to Basque) elements when speaking English than younger learners. Since Spanish and English are both Indo-European languages, whereas Basque is completely unrelated to English, transferring Spanish elements can be regarded as more sensible than transferring Basque elements. Cenoz (2001) suspects that this age trend is due to older learners being more cognitively mature and having higher levels of meta-linguistic awareness.

A further relevant finding stems from the domain of receptive multilingualism. Delsing and Lundin Åkesson (2005) compared 116 Scandinavian youngsters and their parents on their comprehension of spoken and written texts in the related languages Danish, Norwegian, and Swedish. The parents outperformed their children across the board. The authors advanced personal development (larger L1 vocabulary, greater experience in coping with linguistic variation) but also societal changes (increased internationalisation beyond Scandinavia) and recent linguistic changes as possible causes for this finding (Delsing and Lundin Åkesson 2005: 142-144).

Two findings pertaining more directly to cognate comprehension proper derive from studies by Schüppert et al. (forthcoming) and Berthele (2011). Schüppert et al. (forthcoming) tested 116 Danish and Swedish 7- to 16-year-olds on their comprehension of isolated spoken words in the respective other language. Task performance was strongly and positively correlated with the participants' age $(\mathrm{r}=0.61)$. Berthele (2011), finally, asked 163 Swiss German participants aged 13 to 35 to translate written and spoken Swedish and Danish words presented in isolation into German. He found that the participants' age was a strong, positive predictor of task performance, explaining $34 \%$ of the variance.

The findings of these four studies indicate that the ability to put cross-linguistic similarities - and cognate relationships in particular - to good use improves into young adulthood. What is as of yet unclear, however, is whether and how this ability continues to develop past young adulthood. It can be assumed that, in order to guess the meaning of an unknown word with a cognate in a known language, participants need to engage in multiple cognitive processes. As a non-exhaustive list, they may need to (a) draw on their vocabulary knowledge, (b) speculate about plausible interlingual phoneme or grapheme correspondences and (c) mentally transform the stimuli and the potential transfer bases in search of an acceptable interlingual match. These processes could tax cognitive and linguistic resources with rather different lifespan developments, as we will discuss in greater detail in Section 2. According to Welford (1958: 14, cited in Salthouse 2006: 276), age trends in complex 
task performance reflect the demands that the task in question places on improving and deteriorating resources - a suggestion labelled by Salthouse (2006) as still commonly accepted. Thus, to the extent that cognate guessing relies on improving cognitive resources, some further improvement in cognate guessing skills can be expected; to the extent that it relies on deteriorating resources, cognate guessing skills can be expected to decline throughout the adult lifespan.

\subsection{Aims of the present study}

To reiterate, the present study aims to track the lifespan development of the ability to identify crosslinguistic similarities in the lexicon and more specifically to correctly guess the meaning of unknown foreign language words with cognates in known languages. Additionally, it seeks to identify the cognitive and linguistic factors that drive this lifespan development. In particular, four such factors were considered, the possible relevance of which for cognate guessing is discussed in Section 2: L1 vocabulary knowledge, foreign language skills, fluid intelligence and working memory. Given possible age-related differences in the extent to which foreign language learners can cope with spoken versus written stimuli (e.g. Brändle 1986, Krakenberger 2014), both these aims were pursued with respect to both the written and the spoken modality.

\section{Linguistic and cognitive factors and their lifespan development}

\subsection{L1 vocabulary knowledge/crystallised intelligence}

All participants in this study share the same related languages as L1s (Swiss German dialect and Standard German) that may serve as a 'bridge' towards understanding Lx (Swedish) stimuli. But even within a population with the same bridging languages as L1s, differences in L1 experience and breadth of vocabulary may give rise to inter-individual variance in cognate guessing accuracy (see also Teleman 1981). Additionally, experience in dealing with L1 material that deviates (lexically, phonetically, phonologically, syntactically, stylistically etc.) from one's own L1 norms is likely to be a useful asset when trying to make sense of words in a related unknown language (see Delsing and Lundin Åkesson 2005; Teleman 1981). For instance, participants who are highly accustomed to dialectal variation in vowel pronunciation in the L1 may be able to more readily recognise vowels in a related but unknown language as variants of an L1 vowel. This assumption ties in with findings that Lx comprehension is higher in participants with a dialect background (Berthele 2008; Gooskens et al. 2011), as such participants are exposed to a high degree of (in particular) phonological variation within similar linguistic systems on a daily basis. To the extent that an L1 vocabulary measure captures such experience, it can be expected to be associated with cognate guessing accuracy. 
From a lifespan perspective, L1 vocabulary measures are typically subsumed under the label of crystallised intelligence (Gc). This means that they largely reflect the effects of learning and experience and that they show rapid increase throughout childhood and remain stable or show some further improvement in adulthood (e.g. Baltes 1999; Kray and Lindenberger 2007; Salthouse 2006; Singer et al. 2003; Verhaeghen 2003). That said, participants can be assumed to continually gain experience in dealing with deviating L1 speech. To the extent that cognate guessing is dependent on L1 vocabulary knowledge and linguistic experience, then, cognate guessing accuracy should develop steeply into young adulthood and should remain stable or even keep improving somewhat throughout adulthood.

\subsection{Foreign language skills}

Having an L1 that is related to the Lx in which the stimuli are presented obviously does not preclude readers or listeners from drawing on their knowledge of foreign languages when trying to guess the meaning of Lx cognates. Cognate guessing success has been found to show a positive correlation with the number of languages in the participants' repertoires (Berthele 2011; Berthele and Lambelet 2009). That said, what appears to be more crucial than the sheer number of languages in the participants' repertoires is whether they have good to excellent competences in two or more language varieties that are relatively closely related to one another as well as to the Lx. Berthele and Lambelet (2009) found that natively French- and Italian-speaking readers with above-average competences in one additional Romance language outperformed those with above-average competences in another non-Romance language on a cognate guessing task with Romansh and Romanian targets. Similarly, Berthele (2011) found that self-assessed competences in a Germanic foreign language, viz. English, helped to predict the cognate guessing success of German-speaking participants on tasks featuring other Germanic languages. As pointed out in Section 2.1, standarddialect bilingualism may likewise be associated with better cognate guessing skills. A 'related bi- or multilingualism' advantage has not been found in all studies, however: Van Bezooijen et al.'s (2012) Frisian-Dutch bilinguals performed on par with non-Frisian Dutch participants on a cognate guessing task with isolated Danish words.

Knowledge of related languages may provide a boost in cognate guessing success due to the higher number of potentially useful transfer bases (e.g. Swarte et al. 2013). Additionally, multilinguals in related language varieties may be able to distil cross-linguistic patterns from their repertoires and on the basis thereof formulate speculative rules about plausible cross-linguistic correspondences in a process called abduction (Berthele 2011). By way of example, an English-German bilingual may 
observe that German post-vocalic [f] often corresponds to English [p] in word pairs such as tiefdeep or Schiff-ship. The bilingual may then speculate that the [f]-[p] pattern is a plausible crosslinguistic correspondence. When confronted with the Lx (Dutch) word dorp 'village', for instance, she might thus guess more confidently that it may be a cognate of German Dorf.

Since foreign language skills vary as a function of age (e.g. due to schooling), this factor alone may give rise to age effects in cognate guessing skills. Our Swiss participants can all be assumed to be highly accomplished dialect-standard bilinguals. Additionally, most of them have at least some knowledge of French and English, which are compulsory school subjects. Of these, knowledge of English was considered the key variable to be tested, English being a Germanic language related to both the participants' L1s (dialect and standard) and the Lx (Swedish).

\subsection{Fluid intelligence}

L1 vocabulary knowledge and foreign language skills are considered crystallised resources. In contrast to such measures of acculturated knowledge, measures representing non-verbal reasoning and problem-solving skills tend to show a largely monotonic age-related decline after increasing sharply into young adulthood (see Baltes et al. 1999; Kray and Lindenberger 2007; Salthouse 2006). Such reasoning and problem-solving skills are subsumed under the label of fluid intelligence (Gf).

Cognate guessing tasks can be assumed to tax the participants' ability to link unknown words to known words. Lacking context, participants are forced to derive the meaning of these unknown words on the basis of their formal similarity to known words alone. The successful identification of such similarities may depend on the participants' ability to deal flexibly with new information and to solve problems creatively, i.e. on their Gf. Often, moreover, the formal similarity has been obfuscated, e.g. due to the operation of sound laws. In such cases, successful cognate guessing may require the participants to speculate about plausible interlingual grapheme, phoneme and morpheme correspondences, possibly by means of abduction (see Section 2.2). The pattern recognition necessary for abduction could draw on the participants' Gf.

\subsection{Working memory}

Working memory (WM) refers to the ability to briefly maintain and manipulate new information (Baddeley and Hitch 1974). It should not be confused with short-term memory, which can be conceived of as a mere information storage device without processing capabilities (e.g. Park and Payer 2006; see also Cowan 2008). Like Gf measures, measures of WM show rapid increases during childhood (Gathercole 1999) and decline steadily after reaching their peak in young adulthood (Park and Payer 2006). 
For our purposes, age-related changes in WM are relevant when we consider its importance in accounting for individual differences on higher-order cognitive tasks as diverse as complex learning, mental arithmetic and reasoning (see Engle et al. 1999). Engle and colleagues argue that the centrality of WM in a wide variety of tasks is primarily due to its role in focussing attention on what is relevant in a given situation. This factor alone may result in WM-driven inter-individual differences in cognate guessing accuracy. Additionally, cognate guessing tasks can be hypothesised to require the participants to retrieve several known vocabulary items from long-term memory as potentially useful transfer bases via which the Lx stimuli may be decoded. The search for the most suitable transfer bases may entail the mental transformation of the orthography or phonology of several potential transfer bases and of the Lx stimulus at hand along the lines of plausible interlingual correspondence rules (see Section 2.2) as well as a comparison of the results of this process. Participants with a higher WM capacity may be able to retrieve, transform and compare more forms simultaneously without losing track of them, potentially resulting in their making more informed guesses. Consequently, a contribution of WM capacity to cognate guessing success may be expected. Moreover, in the case of spoken stimuli, a well-functioning WM system may help to preserve the stimuli themselves during the retrieval, transformation and comparison process. In the case of written stimuli, this factor is presumably of less importance if the stimuli are displayed throughout.

\subsection{Implications for age trends in cognate guessing}

All four factors considered tend to show age-related increases throughout childhood and adolescence. To the extent that cognate guessing relies on these resources, an age-related increase in cognate guessing skills up to young adulthood is thus to be expected. If cognate guessing relies more strongly on crystallised resources such as L1 vocabulary knowledge and experience and foreign language skills, cognate guessing success will remain at a fairly high level throughout adulthood or even show some additional increase. If resources that deteriorate with age, such as fluid intelligence and working memory, are more important in cognate guessing, cognate guessing performance will decline throughout adulthood. On the whole, a non-linear development in cognate guessing skills can be anticipated.

\section{Method}

\subsection{Participants}

We recruited 167 participants aged 10 to 86 years, all of whom native speakers of a Swiss German dialect. They did not report any knowledge of Swedish or of related North Germanic languages. 
Language experts such as language or linguistics students or interpreters were filtered out a priori. All participants reported normal or corrected-to-normal vision and hearing. They gave their written informed consent before participation and were financially compensated for their participation and travelling expenses.

\subsection{Tasks and procedure}

The research project reported on here is part of a larger project (Multilingualism through the lifespan, SNSF-130457). All participants took part in tasks for two other subprojects as well. The entire task battery lasted about 2.5 to 3 hours (pauses included). Data collection sessions took place in a quiet room at the participants' convenience. Not all variables extracted are of primary interest to the subproject discussed in this article. Here we describe only the tasks and variables directly relevant to our present research questions. Before completing the tasks, all participants filled in a language background questionnaire.

\subsubsection{Cognate guessing task}

The cognate guessing task was made up of Swedish words. Swedish, like the participants' L1s (Swiss German and Standard German), belongs to the Germanic language family, but there is no tradition of receptive multilingualism between present-day speakers of (Swiss) German and Swedish. Cognate guessing in Swedish can therefore safely be considered to be a new experience for the participants. A potentially conducive effect of prior contact with the Lx on cognate guessing (see Delsing and Lundin Åkesson 2005; Jensen 1989) can be assumed to be minimal.

The cognate guessing task consisted of two blocks featuring 50 different Swedish words each. One block consisted of written words, the other of spoken ones. The 50 spoken words were recorded by a female native speaker of Central Standard Swedish. The complete list of stimuli is available in the appendix. $2 \times 45$ words ('target words') could in theory be understood by our participants thanks to the existence of German, English or French translation-equivalent cognates. $2 \times 5$ words did not have any German, English or French translation-equivalent cognates and were in principle unintelligible to the participants ('profile words' in EuroCom parlance, see Stegmann and Klein 1999). The selection of the target words was fine-tuned by a pilot run with 19 Swiss German students. This allowed us to select stimuli that would be translatable by some varying proportion of the participant sample whilst avoiding floor and ceiling effects. The target words therefore show varying degrees of formal overlap with their German, English or French cognates. However, the number of words showing complete formal overlap with their German, English or French cognates was limited in order to avoid ceiling effects. Similarly, the number of relatively short auditory 
stimuli featuring, in particular, fricativised onsets was limited so as to limit floor effects. ${ }^{1}$ The profile words were included to allow us to verify whether the participants did indeed not have any substantial prior lexical knowledge of Swedish. We decided a priori that any participant able to translate more than two profile words in a given block correctly was to be excluded from the analysis (for a similar filtering function of non-cognates in a cognate guessing task, see Kürschner et al. 2008).

The task was administered on a laptop. Participants were informed that they would be presented with a series of Swedish words, some but not all of which they would likely be able to understand. First they had to indicate whether they thought that they might be able to translate the word presented into German. If so, a text box appeared in which they could enter a translation suggestion.

The two blocks (written and spoken) were presented in random order and within each block, the items were presented in random order, too. Target and profile words were interspersed. Written stimuli were presented on the computer screen, and spoken stimuli were played once through both channels of the headphones. Written stimuli remained on-screen until the participants indicated whether they would attempt a translation. Before each block, a training run with five words took place, after which participants could notify the experimenters in case of problems.

Every translation was marked as correct or incorrect. By doing so we do not intend to pass judgement on the reasonableness of the answers provided, merely on their correctness. For instance, translating Sw. kyssa 'to kiss' as Gm. Kissen 'pillow' is perfectly reasonable in the absence of con- and co-textual cues but happens to be incorrect. The scoring protocol is provided in the appendix.

\subsubsection{Linguistic and cognitive tasks}

A measure of vocabulary knowledge in the participants' language of literacy (Standard German) was extracted using Schmidt and Metzler's (1992) Wortschatztest (WST). This paper-and-pencil task consists of 42 series of words and non-words, the participants' task being to tick the existing German word present alongside five orthographically and phonotactically permissible nonwords. The target words ranged from the fairly frequent but educated (e.g. Ironie 'irony') to the highly arcane (e.g. Heddur, a kind of aluminium alloy). One point is awarded for each correctly identified target word.

1 Swedish /k/ and /sk/, for instance, are typically realised as [S] and [乌], respectively when followed by a front vowel, e.g. kämpa ['ઈعmpa] 'to fight' and skinn [乌In] 'skin'. 
Fluid intelligence was measured using the second set of Raven's (1962) advanced progressive matrices. This set contains 36 abstract puzzles in which eight patterns are presented in a 3-by-3 grid. The task is to select the missing ninth pattern that fits logically within this sequence from a list of eight possible alternatives presented underneath the grid. One point is awarded for each correct answer.

Working memory capacity was assessed using a German-language backward digit span task (BWDS; Tewes 1991: 53-54). In a BW-DS task, participants are presented with auditory digit sequences which they need to repeat back verbally in reversed order. The length of the sequences increases from two to eight digits, and each level consists of two sequences. Participants proceed to the next level if they can produce at least one wholly correct backward repetition at the current level. The task is aborted when the participant fails to provide at least one out of two backward sequences, or after the second eight-digit sequence. In order to keep the digit sequence presentation rate constant across testing sessions and across experimenters, the sequences were pre-recorded in Swiss Standard German. The BW-DS measure indicates how many (out of 14) correct responses were provided.

English proficiency, finally, was assessed by means of a 20 -item multiple choice grammar test (the first 20 items from the Oxford Placement Test [Allen 1992]) and a 25-item C-test ${ }^{2}$. The reason why grammar-based rather than vocabulary-based tests were used is that another subproject focussed on grammatical disambiguation strategies in English. That said, L2 grammar test scores and L2 vocabulary test scores are usually substantially correlated (e.g. Shiotsu and Weir 2007). These tests should thus provide an adequate proxy of English vocabulary knowledge, too.

\subsection{Statistical tools}

For the analyses presented in this article, we fitted the correctness of the individual translations on the cognate guessing task in function of various variables. Doing so required modelling the binary dependent variable ('correct' vs 'incorrect') in logistic models with crossed random effects representing the participants and the stimuli. Where the relationships between the predictor covariates and the dependent variable were approximately linear, we made use of the generalised linear mixed model (GLMM). In cases where the relationships were decidedly non-linear, we used the generalised additive mixed model (GAMM), which can cope with such non-linearities. GLMMs and GAMMs were fitted using the lme4 (Bates et al. 2013) and mgcv (Wood 2014) packages for R

2 Increasing your confidence in listening, available from the website of the Language Centre of the University of Rostock: http://www.sprachenzentrum.uni-rostock.de/einstufungstests/c-test/c-test-englisch/ (last accessed 28 January 2014) 
( $\mathrm{R}$ Core Team 2013), respectively. The raw data as well as the $\mathrm{R}$ code used to analyse them are freely available from http://dx.doi.org/10.6084/m9.figshare.936924, allowing those interested to fully reproduce our results or carry out their own analyses.

In deference to readers unfamiliar with mixed-effects and additive modelling, we will base our discussion mainly on graphical representations of the models computed. For reasons of space, we cannot present the logic behind mixed-effects and additive modelling in fine detail. Briefly, mixed models describe the outcome variable as a function of fixed effects and random effects. Fixed effects can loosely be defined as population-level effects that are expected to hold across participants and items. Random effects model by-participant and by-item adjustments to these grand effects. For our present purposes, it is the fixed effects that are of interest. Nevertheless, it is necessary to include random effects in our analyses as well for reasons outlined by Jaeger et al. (2011) and Schielzeth and Forstmeier (2009).

GLMM-based analyses have come to the fore in linguistic and psycholinguistic research in recent years, and readers interested in the technicalities are referred to accessible introductions to linear mixed-effects modelling geared towards language researchers by Baayen (2008), Baayen et al. (2008) and Jaeger (2008). Generalised additive modelling is gaining more popularity in language research, too (see, e.g., Wieling et al. 2011 for an example in dialectology). For an applied introduction to the generalised additive model and its close cousin, the generalised additive mixed model, we refer to an introduction by Zuur et al. (2009: Ch. 3 and 13).

\section{Results}

\subsection{Data description and inspection}

\subsubsection{Participant sample}

Four out of 167 participants were not able to complete the cognate guessing task due to computer malfunctions. The data of four further participants were excluded from the analyses due to missing predictor data. This left a total sample of 159 participants. Their distribution across the age

Table 1: Main demographic characteristics of the participant sample

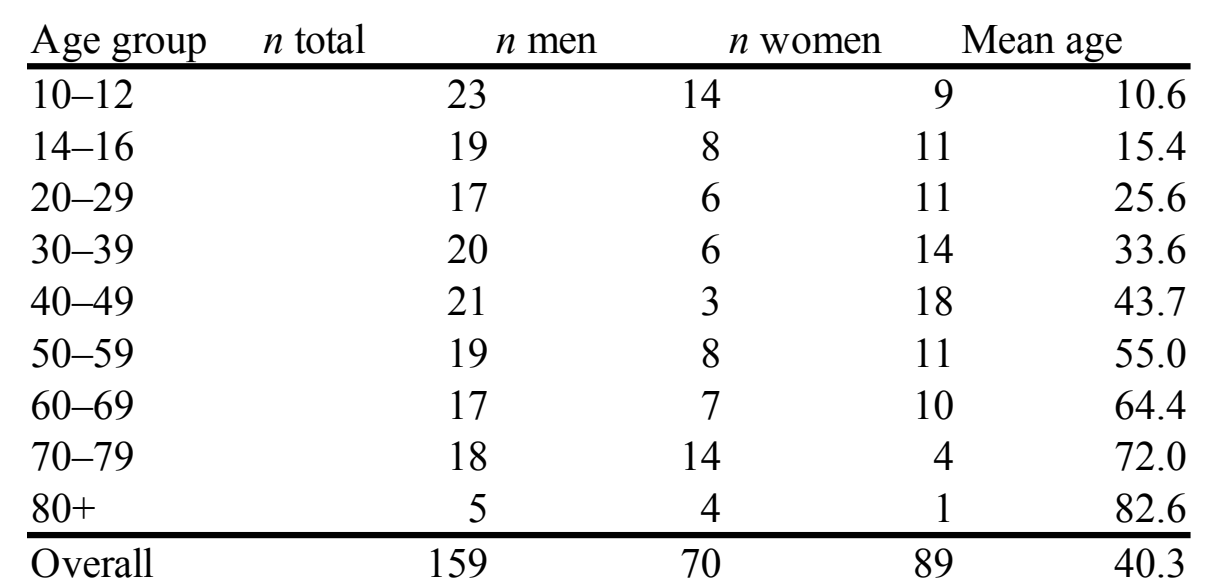


continuum and between the sexes is given in Table 1. Note that the two sexes are not evenly represented across the age groups: the age groups 10-12, 70-79 and 80+ are dominated by men, whereas the other age groups consist mainly of women. When investigating age trends in our sample, it is therefore necessary to take into account the participants' sex as a potential confound variable.

\subsubsection{Cognate guessing data}

The cognate guessing task does not appear to have been overly easy or difficult, as evidenced by the lack of floor and ceiling effects for the outcome variables of interest, viz. the number of correctly translated target stimuli in the two modalities (see Table 2). Moreover, none of the participants was able to correctly translate more than two out of five profile words in any modality. Therefore, no participants were excluded from the analyses on the grounds of having substantial prior knowledge of Swedish. The fact that some participants managed to translate some profile words correctly can most likely be attributed to a small degree of incidental learning, e.g. during holidays or due to popular culture. Such prior incidental learning, however, might be associated with higher translation accuracy for target words, too. In order to account for this possibly confounding effect in our analyses, we created a binary variable that indicates whether a participant had been able to translate at least one profile word correctly, which was the case for a total of 29 participants.

Table 2: Summary data for the number of correctly translated stimuli per participant $(n=159)$ in the cognate guessing task.

\begin{tabular}{llrlrrrr} 
& & Max & \multicolumn{3}{c}{ Range } & Median & Mean SD \\
& & \multicolumn{7}{c}{ Lower } & Upper & & \\
\hline \multirow{2}{*}{ Written } & Target stimuli & 45 & 2 & 33 & 19 & 18.6 & 7.5 \\
& Profile stimuli & 5 & 0 & 2 & 0 & 0.1 & 0.2 \\
\multirow{3}{*}{ Spoken } & Target stimuli & 45 & 2 & 27 & 17 & 16.5 & 5.4 \\
& Profile stimuli & 5 & 0 & 2 & 0 & 0.2 & 0.4
\end{tabular}

Turning briefly to the target stimuli, we find that three spoken words were not translated correctly by any of the participants: ['JE:gعl] (kägel 'cone'), ['ty:dlıg] ( tydlig 'clear') and [乌ærm] (skärm 'screen'). Since these items had no discriminatory power, they were discarded from the analyses, leaving 87 items for 159 participants. None of the target words was translated correctly by all of the participants. This left a total of 13,833 target word responses for the analyses.

\subsubsection{Linguistic and cognitive covariates}

The tally of number of known foreign languages includes all languages listed by the participants in the language background questionnaire except for Swiss German and Standard German (both have L1 status for all participants), sign languages, and Ancient Greek and Latin. A mere six participants 
listed more than five known foreign languages. In order to prevent these participants from exerting undue influence on the analyses, they were collapsed into the same category as participants with five foreign languages. Apart from German, English and French, the languages listed were Italian (83), Spanish (55), Portuguese (7), Tagalog (5), Serbian (4), Hungarian, Romansh (3), Cebuano, Dutch, Greek, Russian, Swahili (2), Arabic, Bahasa, Catalan, Czech, Hebrew, Romanian, Tamil, Telegu, Thai and Turkish (1). Thus, only two participants had some minimal knowledge of a Germanic foreign language other than English, viz. Dutch. Summary data for this variable are presented in Table 3. The sample lifespan trajectory of the number of foreign languages known (upper left panel of Figure 1) is roughly stable throughout the adult lifespan but shows an increase throughout childhood and adolescence as the result of schooling.

Table 3: Summary data for the linguistic

and cognitive measures $(\mathrm{n}=159)$

$$
\text { Range Median Mean SD }
$$

\begin{tabular}{llrrrrr}
\multicolumn{7}{c}{ Lower Upper } \\
\hline $\begin{array}{l}\text { Number of foreign } \\
\begin{array}{l}\text { languages } \\
\text { English test }\end{array}\end{array}$ & 1 & 5 & 3 & 3 & 1.1 \\
& Multiple & 0 & 20 & 15 & 13.7 & 4.6 \\
& choice & & & & & \\
& C-test & 0 & 24 & 16 & 14.7 & 6.7 \\
WST & Overall $^{4}$ & -2.4 & 1.4 & 0.3 & 0.0 & 1.0 \\
Raven & & 4 & 41 & 34 & 30.2 & 8.9 \\
BW-DS & & 0 & 35 & 19 & 17.8 & 8.1 \\
& & 2 & 12 & 6 & 6.4 & 1.9
\end{tabular}

English proficiency was measured using a multiple choice test and a C-test. The scores on both tests are unsurprisingly strongly correlated $(r=0.85)$ and were collapsed into one overall variable. In order to weigh both subtask scores evenly in this composite measure, we $z$-normalised them, i.e. centred them at their means and divided them by their respective standard deviations, before averaging them for each participant. This guarantees that the composite measure correlates equally strongly with both subtask scores $(r=0.96)$. Table 3 presents summary statistics for the original subtask scores as well as for the composite measure. The lifespan trajectory of the composite measure (upper right panel of Figure 1) shows that English proficiency reaches its zenith around age $25-30$ and decreases from that point onwards.

3 This includes all languages listed by the participants except the L1s Swiss German and Standard German, sign languages, and Ancient Greek and Latin. Participants who listed five or more languages $(n=6)$ were collapsed into the same category.

4 The overall English score is the average of the $z$-normalised scores on the multiple choice test and C-test. 

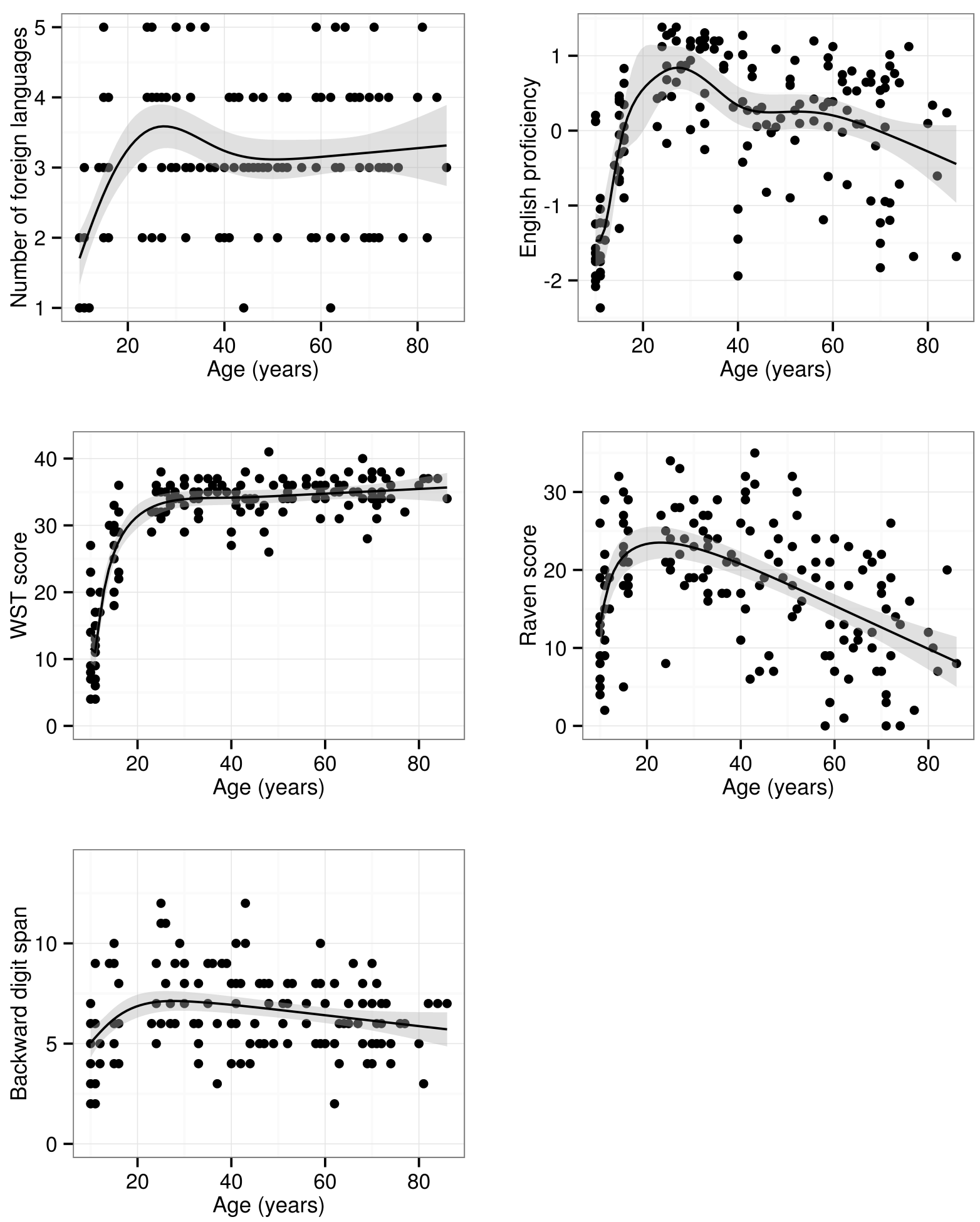

Fig. 1: Sample age trends in the predictor covariates

Next, Table 3 presents summary data for the scores on the German vocabulary task and the Raven task (representing fluid intelligence). The sample lifespan trajectories of these variables are given in the middle panels of Figure 1 and conform to the canonical lifespan trajectories for the constructs that they represent. 
Lastly, Table 3 presents summary data for the BW-DS measure (representing WM capacity). The sample lifespan trajectory of this variable, presented in the bottom panel of Figure 1, indicates that the WM variable does not seem to be subject to a strong age trend. The BW-DS task, while in common use in language studies (for a recent example, see Martin and Ellis 2012), is a rather quickand-dirty task for measuring WM and is considered by some (e.g. Engle et al. 1999; Park and Payer 2006) to be a measure of short-term memory instead. Short-term memory is less affected by ageing than is WM (Park and Payer 2006).

These variables are intercorrelated to a certain extent $(0.16 \leq r \leq 0.70)$. Substantial multicollinearity can make it difficult to gauge the influence of any one predictor on the outcome variable in regression models. However, a numerical check revealed that the degree of multicollinearity between these five variables, when properly centred at their means, is no cause for concern $(\kappa=3.5$; see Baayen 2008: 182).

\subsection{Age trends in cognate guessing skills}

As expected (see Section 2.5), exploratory analyses indicated that the relationship between cognate guessing skills and age is non-linear in both modalities. We therefore fitted translation accuracy as a function of a non-linear age trend in logistic GAMMs with crossed random intercepts for participants and items. In a first step, we fitted separate models for the written $(n=7,155)$ and for the spoken target words $(n=6,678)$. In addition to a non-linear age trend, these models included binary variables representing the participants' sex and whether the participants provided at least one correct profile word translation. The two models are summarised numerically in Tables 4 and 5. 
Table 4: GAMM modelling correctness of translation for written target words in function of age.

Subtable (a): Parametric terms (in log-odds), their standard errors and their significance.

Subtable (b): Non-linear term.

Subtable (c): Estimated standard deviations

of the random effects $(\sigma)$.

(a) Parametric terms

\begin{tabular}{llr} 
& Estimate \pm SE & $p$ \\
\hline Intercept & $-0.74 \pm 0.29$ & 0.01 \\
Male participant & $-0.13 \pm 0.14$ & 0.38 \\
& & \\
$\geq 1$ correct profile & $0.92 \pm 0.19$ & $<0.001$ \\
word translation & &
\end{tabular}

(b) Non-linear term

\begin{tabular}{lcccc} 
& Est. df & & $\chi^{2}$ & $p$ \\
\hline Age & & 3.5 & 91.8 & $<0.001$
\end{tabular}

(c) Random effects

\begin{tabular}{ll} 
& $\sigma$ \\
\hline $\begin{array}{l}\text { Random intercept by } \\
\text { participant }\end{array}$ & 0.75 \\
Random intercept by & \\
item & 1.81
\end{tabular}


Table 5: GAMM modelling correctness of translation for spoken target words in function of age.

Subtable (a): Parametric terms (in log-odds), their standa1 and their significance.

Subtable (b): Non-linear term.

Subtable (c): Estimated standard deviations

of the random effects $(\sigma)$.

(a) Parametric terms

\begin{tabular}{lcr} 
& Estimate \pm & $p$ \\
\hline Intercept & $-1.05 \pm 0.38$ & $<0.01$ \\
Male & $-0.06 \pm 0.14$ & 0.64 \\
participant & & \\
$\geq 1$ correct & $0.29 \pm 0.18$ & 0.11 \\
profile word & & \\
translation & &
\end{tabular}

(b) Non-linear term

\begin{tabular}{lrrl} 
& Est. df & $\chi^{2}$ & $p$ \\
\hline Age & 5.0 & 86.0 & $<0.001$
\end{tabular}

(c) Random effects

\begin{tabular}{ll} 
& $\sigma$ \\
\hline Random & 0.67 \\
intercept by & \\
participant & \\
Random & \\
intercept by & 2.34 \\
item &
\end{tabular}



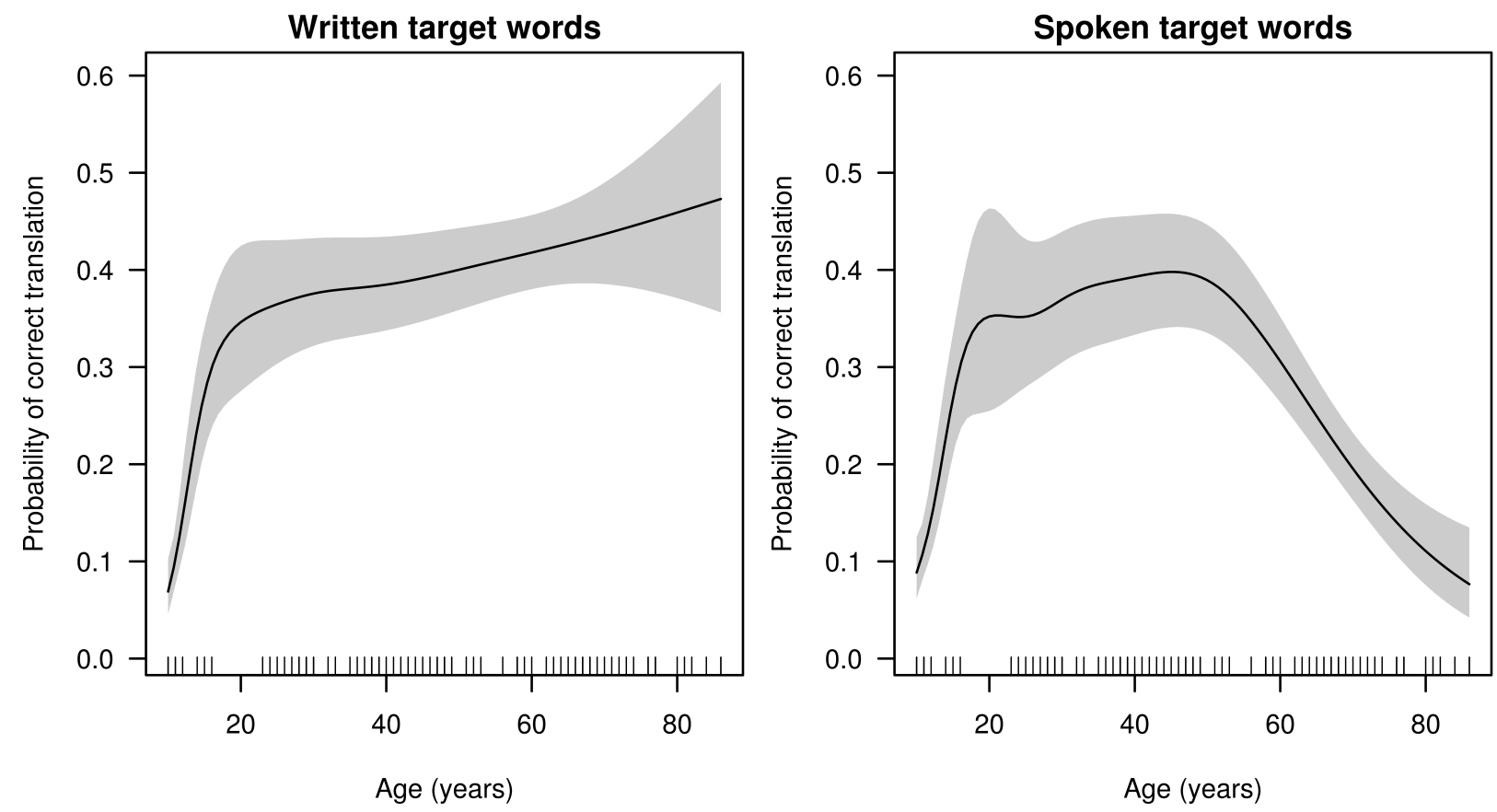

Fig. 2: Age trends for GAMM-fitted translation accuracy in the written (left) and spoken modality (right) with $95 \%$ confidence bands. The trend lines represent the modelled probabilities for a typical female participant who did not translate any profile word correctly.

The functional forms of non-linear GAMM terms cannot be derived from this numerical output and need to be judged by eye. The age trends, presented in Figure 2, appear to differ between the two modalities. Cognate guessing skills in both modalities show rapid improvement throughout childhood and adolescence. However, the age trends diverge in adulthood. Cognate guessing skills show some further improvement throughout adulthood in the written modality, but in the spoken modality, cognate guessing skills start to worsen from about age 50 onwards. Removing the nonsignificant potential confound variables does not appreciably change these trends.

We verified whether these diverging age trends are statistically reliably different from one another by fitting two additional GAMMs with crossed random intercepts for participants and items in which the accuracy of all 13,833 responses were modelled jointly in terms of stimulus modality and a non-linear age term. The variable indicating whether the participant provided at least one correct profile word translation was included as well, as was the participants' sex. In the first model, stimulus modality was allowed to interact with sex and profile word translation but not with the non-linear age term. In the second model, stimulus modality was allowed to interact with the age term as well. The second, more complex, model proved to be a major improvement over the first as indicated by the sub- stantial decrease in the AIC value $(\triangle \mathrm{AIC}=144)$. Thus, the age trends in the 
two modalities are indeed reliably different from one another. In the next section, we explore to what extent these diverging age trends can be explained in terms of linguistic and cognitive factors.

\subsection{Effects of linguistic and cognitive factors}

We now turn to the statistical modelling of the correctness of the translations provided by the participants in function of main effects for the following variables: number of foreign languages known, English proficiency, WST score, Raven score and backward digit span, as well as the potential confound variables of sex and profile word translation. To keep this presentation tractable, we fitted separate models for the written items $(n=7,155)$ and for the spoken ones $(n=6,678)$. Exploratory analyses did not reveal any substantial non-linear patterns between the predictor covariates and the outcome variables. Both subsamples were therefore modelled with the generalised linear mixed model (GLMM). Prior to the analyses, all covariates were centred at the means of these subsamples as recommended by Baayen (2008: 254-255).

\subsubsection{Written items}

The GLMM for the written target items is presented in Table 6. This table contains both the fixed effect part of the model and the random effect part. As we mentioned in Section 3.3, it is the fixed effects that are of interest for our present purposes; the random effect parameters are given for the sake of completeness. The fixed effects are presented more accessibly in Figure 3. (Since the model is a logistic model, the plotted partial fixed effects are not straight lines. The effects are modelled linearly in terms of log-odds, but transforming them back into probabilities results in curved trend lines.) 
Table 6: GLMM for written target words. Subtable (a): Fixed effects, their twotailed significance and their effect sizes. Subtable (b): Estimated standard deviations of the random effects $(\sigma)$. All covariates were centred at their sample means. Parameters and effect sizes are expressed in log-odds.

(a) Fixed effects

$$
\text { Estimate } \pm \mathrm{SE} \quad p \quad \text { Effect size } \pm \mathrm{SE}^{5}
$$

\begin{tabular}{lcrr}
\hline Intercept & $-0.91 \pm 0.32$ & $<0.01$ & \\
Male participant & $-0.050 \pm 0.130$ & 0.7 & $-0.1 \pm 0.1$ \\
$\geq 1$ correct profile word & $0.55 \pm 0.17$ & $<0.01$ & $0.5 \pm 0.2$ \\
translation & & & \\
Number of foreign languages & $0.18 \pm 0.07$ & 0.02 & $0.7 \pm 0.3$ \\
English proficiency & $0.35 \pm 0.13$ & $<0.01$ & $1.3 \pm 0.5$ \\
WST score & $0.085 \pm 0.016$ & $<0.001$ & $3.2 \pm 0.6$ \\
Raven score & $0.0061 \pm 0.0103$ & 0.55 & $0.2 \pm 0.4$
\end{tabular}

(b) Random effects

Random intercept by participant

Random intercept by item

Random slope for English proficiency by item

Random slope for WST score by item
0.68

2.04

0.39

0.061

5 Following Baayen et al. (2008), effect sizes were computed as the largest difference in the outcome variable (in logodds) when the predictor variable is allowed to vary along its range. For instance, the centred English proficiency measure spans from -2.4 to 1.4 . Since the parameter estimate for this variable is 0.35 , its effect size equals $0.35 \times$ $(1.4-(-2.4)) \approx 1.3$. 


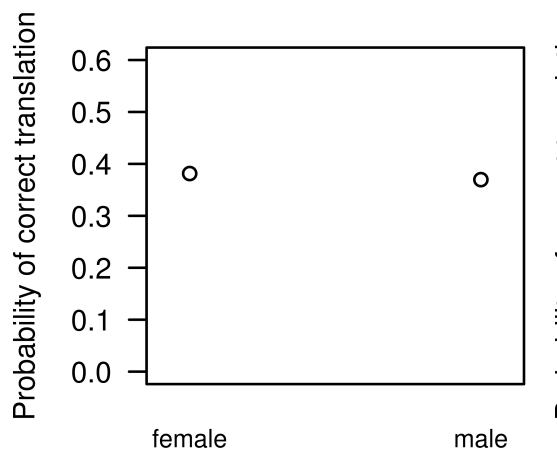

Written target words
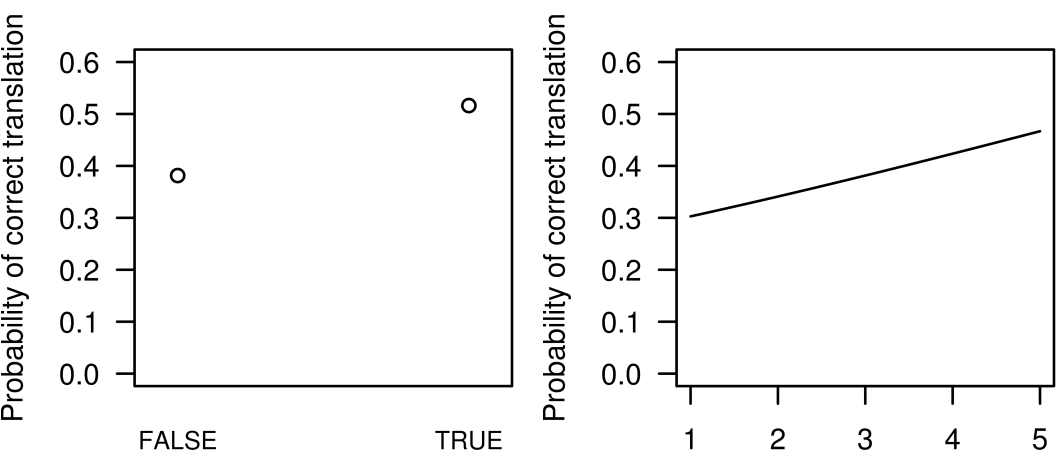

More than one correct profile

Sex

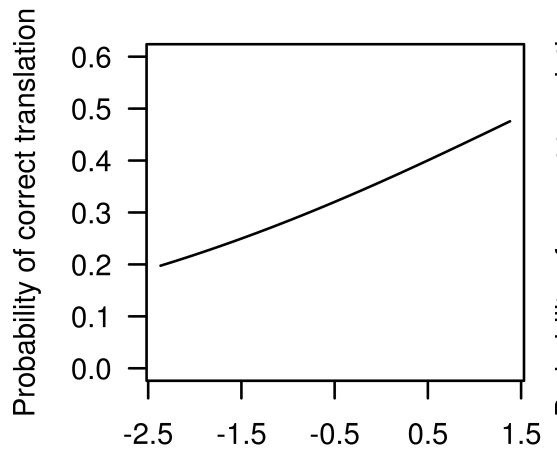

word translation?

Number of foreign languages
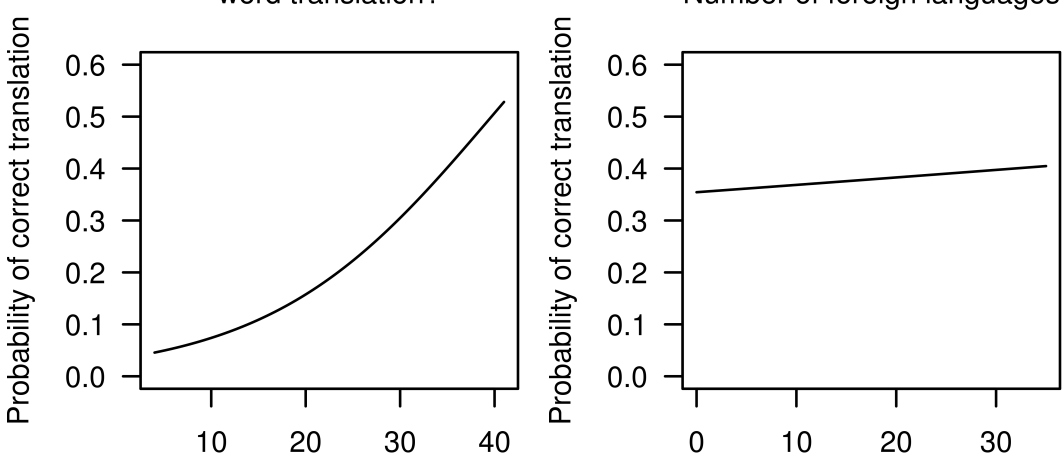

English proficiency

WST score

Raven score

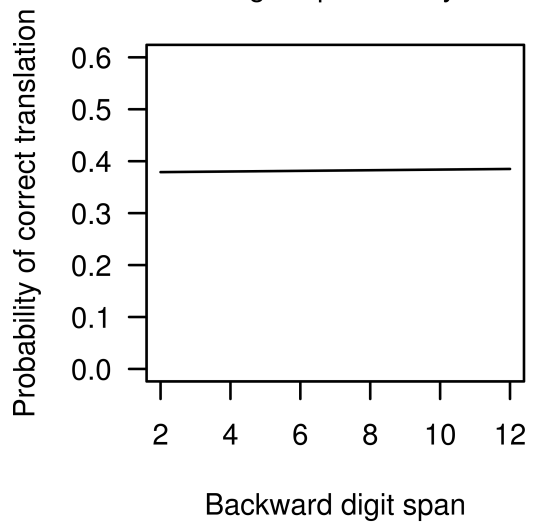

Fig. 3: Partial fixed effects of the GLMM modelling cognate guessing success for written target items

From both Table 6(a) and Figure 3 it can be gleaned that cognate guessing skills in the written modality are most strongly associated with the participants' WST scores (effect size: $3.2 \pm 0.6 \log$ odds), followed by their English proficiency (ES: $1.3 \pm 0.5$ ). The number of foreign languages known plays a significant but relatively modest role (ES: $0.7 \pm 0.3$ ), whereas the effects of Raven score and BW-DS are small and non-significant (ESs: $0.2 \pm 0.4$ and $0.0 \pm 0.4$ ). Removing the nonsignificant terms does not appreciably change the parameter estimates of the remaining effects nor their standard errors. 


\subsubsection{Spoken items}

Table 7 presents the GLMM for the spoken target words. Again, we are mainly interested in the fixed effects, which are plotted in Figure 4. The effects of the covariates differ markedly from those in the written item model in a few respects.

Table 7: GLMM for spoken target words. Subtable (a): Fixed effects, their twotailed significance and their effect sizes. Subtable (b): Modelled standard deviations of the random effects $(\sigma)$. All covariates were centred at their sample means. Parameters and effect sizes are expressed in log-odds.

(a) Fixed effects

\begin{tabular}{lcrr} 
& Estimate $\pm \mathrm{SE}$ & \multicolumn{1}{c}{$p$} & Effect size $\pm \mathrm{SE}^{6}$ \\
\hline Intercept & $-1.0 \pm 0.4$ & 0.01 & \\
Male participant & $-0.25 \pm 0.13$ & 0.057 & $-0.2 \pm 0.1$ \\
$\geq 1$ correct profile word translation & $0.16 \pm 0.18$ & 0.35 & $0.2 \pm 0.2$ \\
Number of foreign languages & $0.014 \pm 0.074$ & 0.85 & $0.1 \pm 0.3$ \\
English proficiency & $0.25 \pm 0.13$ & 0.046 & $0.9 \pm 0.5$ \\
WST score & $0.041 \pm 0.015$ & $<0.01$ & $1.5 \pm 0.6$ \\
Raven score & $0.054 \pm 0.011$ & $<0.001$ & $1.9 \pm 0.4$ \\
Backward digit span & $-0.085 \pm 0.040$ & 0.03 & $-0.8 \pm 0.4$
\end{tabular}

(b) Random effects

\begin{tabular}{lr} 
& \multicolumn{1}{c}{$\sigma$} \\
\hline Random intercept by participant & 0.66 \\
Random intercept by item & 2.51 \\
Random slope for English proficiency by item & 0.39 \\
Random slope for WST score by item & 0.061 \\
Random slope for Raven score by item & 0.028
\end{tabular}

6 Effect sizes were computed as the largest difference in the outcome variable (in log-odds) when the predictor variable is allowed to vary along its range. See Table 6 for an example. 


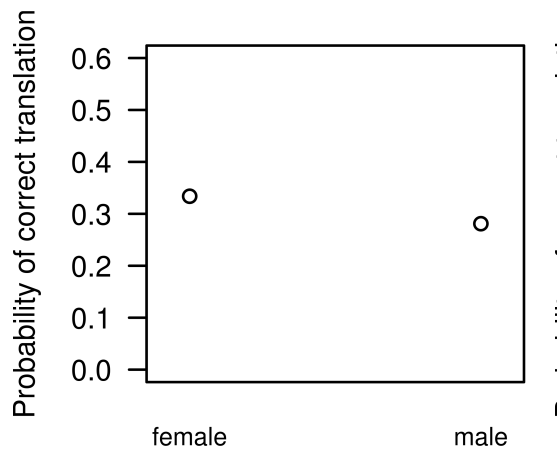

Spoken target words
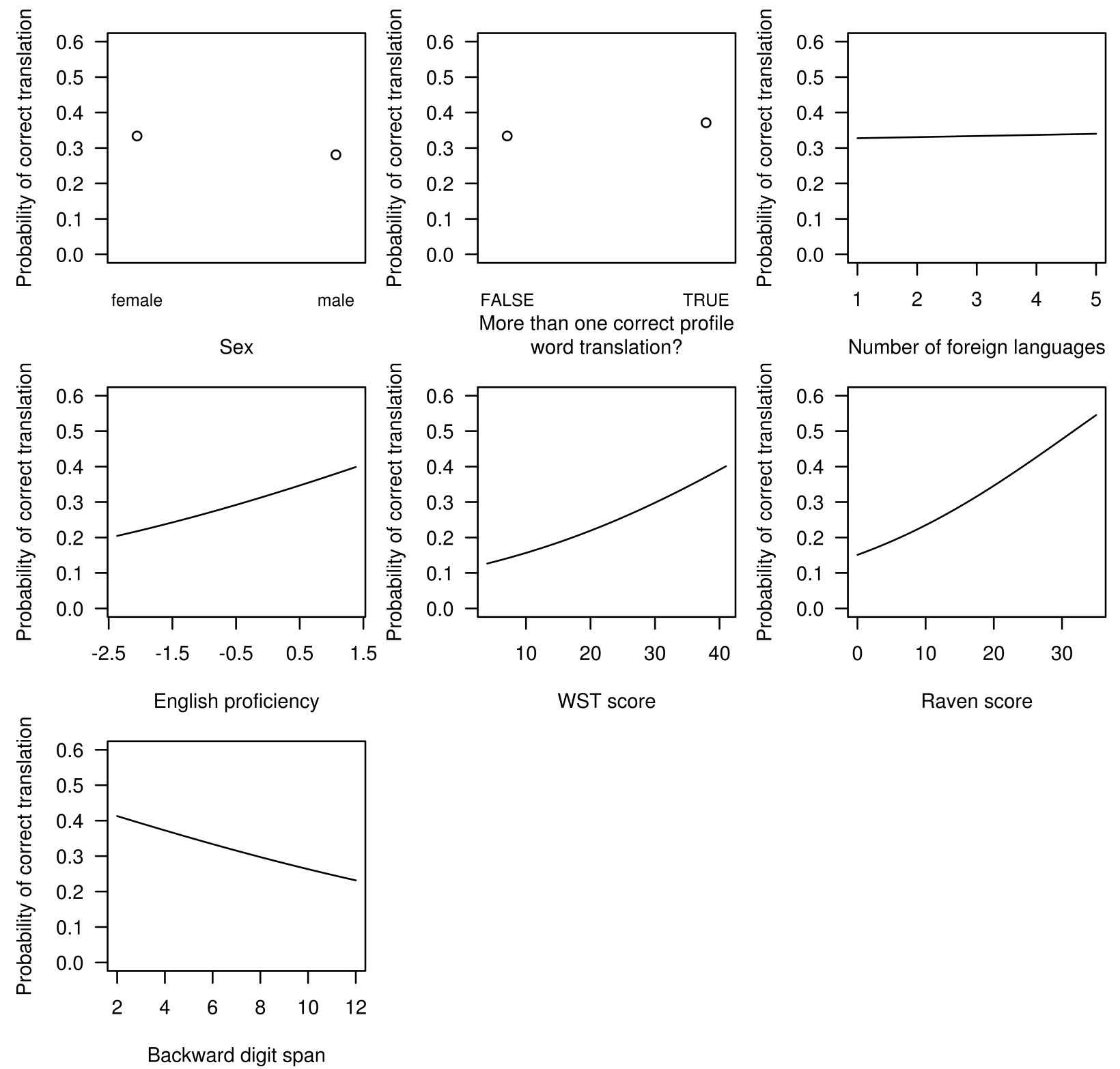

WST score

Raven score

Fig. 4: Partial fixed effects of the GLMM modelling cognate guessing success for spoken target items.

First, the number of foreign languages in the participants' repertoires seems inconsequential (ES: $0.1 \pm 0.3)$. Second, Raven score and BW-DS are now significant predictors with respectable effect sizes. Indeed, Raven score, which is positively associated with target word translation success, has the largest effect size of all predictors (ES: $1.9 \pm 0.4$ ). The effect of BW-DS is a negative one (ES: $-0.8 \pm 0.4$ ), i.e. better performance on the BW-DS task is associated with lower spoken target word translation success. Third, WST score is still positively associated with cognate guessing skills, but its effect size is much smaller (ES: $1.5 \pm 0.6)$. Fourth and last, the effect size of English proficiency is lower than for the written items (ES: $0.9 \pm 0.5$ ), and its two-tailed significance now hovers around 
the 0.05 threshold. Again, removing the non-significant terms from the model does not alter the remaining parameter estimates and standard errors much. The model's random effects are not discussed here but are presented in Table 7(b) for the sake of completeness.

\subsubsection{Variable-by-modality interactions}

A comparison of the fixed effects in Tables 6(a) and 7(a) suggests that the effects of some of the covariates, specifically the number of foreign languages known, WST score, Raven score and BWDS, may differ between the two modalities. It is difficult to compare the results of both analyses directly, however: even if a variable has a significant effect in one modality but not in the other, the effects still need not be significantly different from each other (Gelman and Stern 2006; Nieuwenhuis et al. 2011). In order to assess whether any variables have significantly different effects depending on the modality, both subsets were modelled jointly. In addition to entering into two-way interactions with the other predictors, stimulus modality was added to the model both as a fixed main effect and as a by-participant random slope.

The resultant model is not reported in full here as it does not yield any new insights not provided by the modality-specific GLMMs reported earlier. In brief, however, the by-modality interactions for WST score $(p=0.04)$ and Raven score $(p<0.001)$ were significant at the 0.05 threshold. English proficiency can safely be considered not to enter into a strong interaction with modality $(\mathrm{p}=0.77)$. The effects of the number of foreign languages known and BW-DS may differ according to modality, but the by-modality interactions are not significant at the conventional 0.05 threshold ( $p$ $=0.06$ and 0.07 ). Thus, only the strength of the effects of WST score and Raven score is found to vary statistically significantly between the two modalities.

\section{Discussion}

\subsection{Age trends}

Our first goal was to track the lifespan development of Lx cognate guessing skills. Our results in this respect fit in with findings by Berthele (2011) and Schüppert et al. (forthcoming) as well as more broadly with those by Delsing and Lundin Åkesson (2005) and Cenoz (2001) in that we found an increase in the ability to correctly translate both written and spoken cognates from an unknown related language throughout childhood and adolescence. At the same time, this study substantially widens our understanding of how Lx cognate guessing skills continue to develop past young adulthood. In the written modality, cognate guessing skills seem to show a continued gradual increase throughout the adult lifespan. In the spoken modality, cognate guessing skills appear to be fairly stable from age 20 to about age 50, at which point they start to show a decline. 


\subsection{Linguistic and cognitive predictors}

Welford (1958) suggested that age trends in complex task performance reflect the task's demands on fluid and crystallised resources. Therefore, we explored to what extent cognate guessing skills in the written and spoken modalities are affected by linguistic and cognitive factors that show age trends themselves. The variables considered were (a) the number of foreign languages in the participants' repertoires, (b) English proficiency, (c) L1 vocabulary knowledge, (d) fluid intelligence, indexed by an abstract pattern completion task, and (e) working memory capacity. Of these, (d) and (e) are uncontroversially considered fluid resources, whereas (c) is a crystallised resource. We consider (a) and (b) to be crystallised resources as well since they are to a substantial extent the product of learning and experience.

Of these variables, English proficiency emerged as a respectable predictor of cognate guessing skills in both modalities. As a Germanic language that is closely related to both the Lx in question (Swedish) and the participants' native language varieties (Swiss German, Standard German), English can provide both useful transfer bases and may speculatively serve as a vehicle for abduction, as suggested by Berthele (2011; see also Section 2.2). Its role, however, is fairly similar in both modalities. This means that it cannot be a main contributor for the age-by-modality interaction in cognate guessing skills. It may, however, contribute to the general increase in cognate guessing skills throughout childhood and adolescence.

To account for the differential age trends in cognate guessing skills in terms of linguistic and cognitive factors, we need to turn to the other variables. The modest continued improvement of written cognate guessing success throughout the adult lifespan suggests a dependence on mainly crystallised resources, whereas the age-related demise of spoken cognate guessing success indicates a stronger reliance on fluid resources (as per Welford 1958). Correspondingly, the most important predictor of written cognate translation success is the L1 vocabulary measure (see Table 6). This finding is consistent with speculations that a well-developed L1 vocabulary is conducive to one's ability to understand closely related languages (see Section 2.1). Simultaneously, it may be interpreted in terms of Berthele's (2011) suggestion that cognate guessing draws on abduction as discussed in Section 2.2: participants with a large L1 vocabulary and, more generally, broad experience in coping with linguistic variation of sundry kinds (regional, social, stylistic etc.) may be in a better position to speculate about plausible inter-varietal form correspondences. In the spoken modality, L1 vocabulary knowledge is still a respectable predictor of cognate guessing skills, but its effect is appreciably weaker (see Table 7). The crystallised resource of L1 vocabulary knowledge 
can therefore provide age-related stability in cognate guessing skills in the written modality, but less so in the spoken modality.

The third crystallised resource under consideration, viz. the number of foreign languages known, turned out to be at best a modest predictor of cognate guessing skills in the written modality (Table 6), and its effect in the spoken modality is negligible (Table 7). It is doubtful that this variable is a main contributor to the age-by-modality interaction in cognate guessing skills. In the present study, only two participants had some minimal knowledge of a Germanic foreign language beside English (Dutch). For the remaining participants, therefore, the additional foreign languages were not obviously useful in providing transfer bases or examples of directly applicable sound correspondences between Germanic languages. A small to negligible effect of knowledge of foreign languages not related to the Lx is consistent with findings by Berthele (2011) and Berthele and Lambelet (2009).

As to the fluid resources, we found that the effects of Gf (Raven score) and WM capacity (BW-DS) were negligible in the written modality. In the spoken modality, by contrast, Gf turned out to be the most important predictor of all. Decreases in Gf from about age 20 onwards (see Figure 1) may therefore contribute to the age-related decline in spoken cognate guessing skills whilst not affecting written cognate guessing skills. We posited that a contribution of Gf to cognate guessing skills could be expected on the grounds that Gf represents a person's ability to deal flexibly with new information and solve novel problems creatively. Moreover, abductive reasoning may be necessary to cope with obfuscated formal resemblances between the L1, L2, .., Ln and the Lx, and such abductive reasoning may draw on the participants' Gf. We will turn to the question of why Gf has a differential effect according to stimulus modality below.

Contrary to our expectations, WM capacity was actually negatively associated with spoken cognate guessing skills when considered jointly with other linguistic and cognitive predictors in a multivariate model (Table 4). In the written modality, however, the effect of WM capacity was negligible (Table 3), and the effect may not be reliably different between the two modalities (Section 4.3.3). At present, we are hesitant to speculate as to the reasons for the negative effect found for spoken target words, given that it clashes with our expectations. For now, we prefer to offer this findings as a spur for a future study, which could measure WM capacity more stringently than we did, e.g. using a latent variable constructed on the basis of multiple WM tasks.

In sum, cognate guessing skills follow a different developmental trajectory depending on stimulus modality, and it seems that a differential reliance on Gf and L1 vocabulary knowledge underlies this 
difference to a substantial degree. But why should Gf and L1 vocabulary knowledge impact cognate guessing skills in the two modalities differentially to begin with? Speculatively, it may be more cognitively challenging to compare phones and phonemes across languages than letters and graphemes. An alternative explanation is that it may be the time pressure associated with auditory stimulus presentation that causes the difference. Spoken items were presented just once, whereas written items remained onscreen until the participants entered their translations. Spoken items thus required above all the quick application of cognitive flexibility; in the written modality, speed was a lesser issue and participants had more time to consider plausible interlingual relationships ('interlingual inferencing', Carton 1971). Thus, differences in time pressure may, on the one hand, account for the presence of a fluid intelligence effect in the spoken modality and the absence of such an effect in the written modality and, on the other hand, for the greater importance of crystallised resources that form the basis of such interlingual inferencing. A similar point was made by Ringbom (1992: 94) about full text comprehension in a related foreign language: the absence of time constraints in reading enables readers to draw on knowledge resources more than in listening. Thus, repeated aural presentation could conceivably have had diminished the differential modality effect since it would have lowered the time pressure associated with the spoken modality. In order to guarantee a minimal ecological validity of the task, however, we had decided to present the stimuli only once - just as in typical oral communication.

\subsection{Residual age trends}

The models in Tables 6 and 7 contain by-participant random intercepts. These capture the residual between-participant variation in cognate guessing performance after the effects of the linguistic and cognitive predictors have been taken into account. While a perfect model is an unattainable goal, this residual inter-individual variation does spur the question whether we did in fact succeed in adequately modelling the age trends found in terms of linguistic and cognitive factors. Systematic inter-individual variation not modelled by the fixed effects should have been largely captured by the by-participant random intercepts in the GLMMs. If there are no residual age effects left unexplained by the fixed effects, we should find no pattern when plotting the by-participant random intercepts as a function of the participants' age. If, on the other hand, we should find some non-randomness in this relationship, we would have to conclude that the fixed effects in the GLMMs could not fully account for the age effects in cognate guessing accuracy. Using (ordinary) GAMs, we can gauge how much variance in the by-participant random intercepts can be accounted for by the participants' age. We therefore fitted separate (Gaussian) GAMs on these random intercepts. Age was the sole predictor in these GAMs, and its effect was modelled non-linearly. 

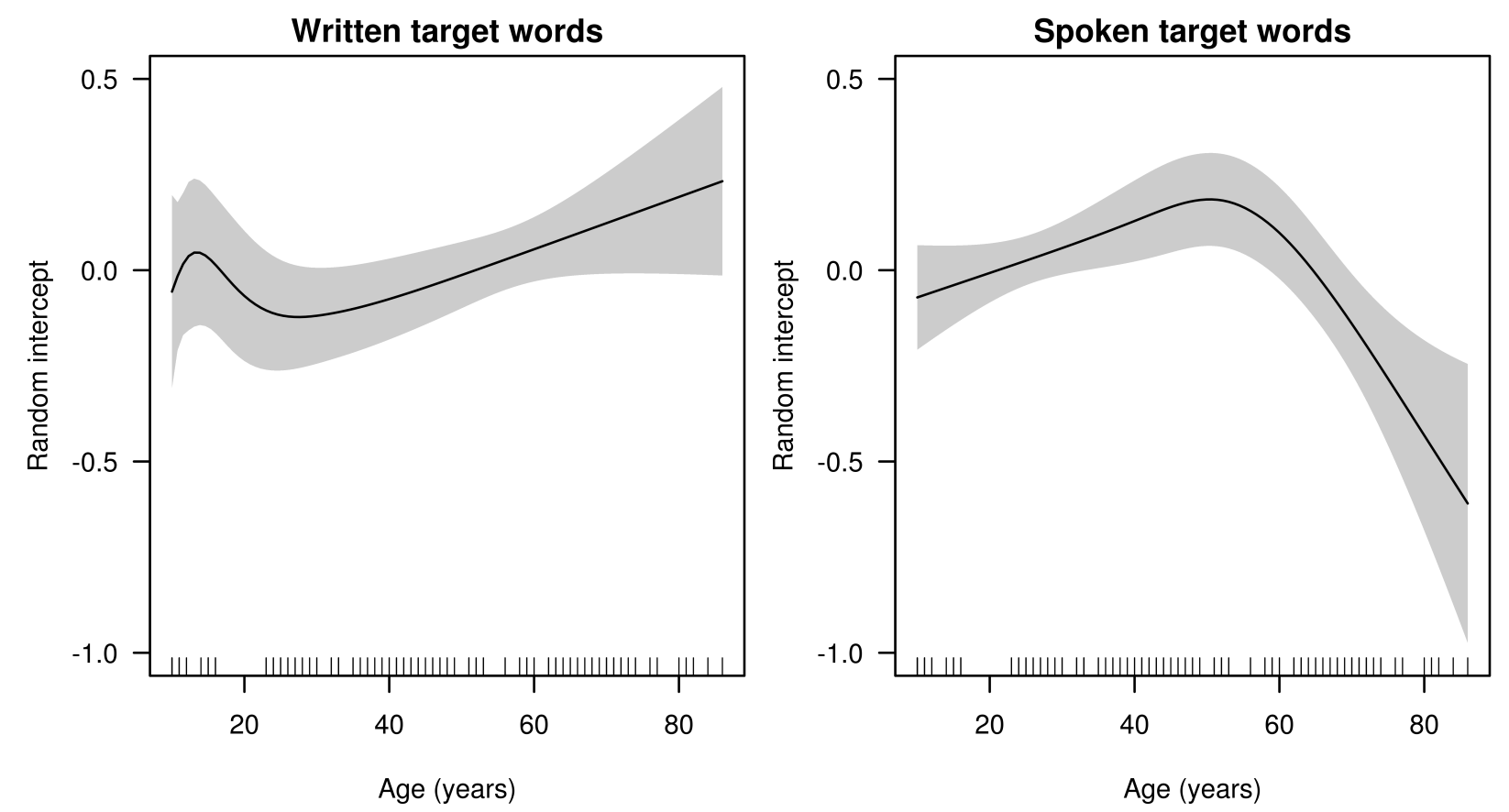

Fig. 5: Residual age effects in the random intercepts.

These GAMs indicate that we were not wholly successful in modelling the age trends in cognate guessing success in terms of linguistic and cognitive factors. As can be seen in the left panel of Figure 5, the fixed effects in the GLMM for written stimuli slightly underestimate the increases in cognate guessing task performance throughout adulthood. Nevertheless, the extent of this underestimation is limited as the non-linear residual age trend can account for merely $4.1 \%$ of the variance in the by-participant random intercepts and is not significant $(F=1.6$, est. $\mathrm{df}=2.8, p=$ 0.17). Similarly, the fixed effects of the participant-related linguistic and cognitive predictors seem to simultaneously slightly underestimate the modest age-related increase in spoken cognate guessing up to about age 50 and (more markedly) the decrease from that age onwards. This nonlinear residual age effect is significant $(F=5.9$, est. df $=2.4, p<0.01)$, but it can still account for only $10.5 \%$ of the variance in the random intercepts.

Summarising, there are still some residual age trends not accounted for by the linguistic or cognitive variables, particularly in the spoken modality. Presumably, these residual trends can further be accounted for by taking more fine-grained measures of the predictor constructs than was possible in the present study. ${ }^{7}$ Additionally, other age-related factors not considered in our analyses may further account for the age-by-modality interaction that we found. One such factor may be hearing acuity. Hearing acuity decreases in older age but may go undetected in self-reports provided by older

7 In an ideal world, these constructs would be measured using multiple tests in a latent-variable approach as recommended by Conway et al. (2005). But even then, vocabulary test scores may underestimate the actual expansion of vocabulary knowledge throughout the lifespan (Ramscar et al. 2014). 
participants (see Gordon-Salant 2005: 17-18). Hearing acuity decreases have been shown to negatively affect novel L1 accent comprehension in older adults (Adank and Janse 2010). On the view that L1 accent comprehension and Lx comprehension rely on the same cognitive machinery (see, e.g., Van Heuven 2008), hearing acuity can be thus hypothesised to be associated with spoken cognate guessing skills, too.

\section{Conclusions and outlook}

In conclusion, cognate guessing skills as measured using a word translation task improve throughout childhood and adolescence. In the written modality, cognate guessing skills show some further improvement throughout adulthood. In the spoken modality, cognate guessing skills remain fairly stable between ages $20-50$ but then start to decline. These differential age trends can partly be accounted for by a differential reliance on Gf and crystallised resources (indexed in particular by L1 vocabulary knowledge) in the two modalities.

In this article, we focused exclusively on inter-individual differences in cognate guessing. However, research on cognate guessing and receptive multilingualism more generally is also interested in the contribution of stimulus-related characteristics, e.g. the degree of formal similarity or corpus frequency, to cognate recognition (e.g. Berthele 2011; Berthele and Lambelet 2009; Gooskens et al. 2011; Kürschner et al. 2008; Möller 2010; Möller and Zeevaert 2010; Van Heuven 2008). An interesting line of further inquiry concerns the interactions between the participant-related linguistic and cognitive variables discussed in this paper on the one hand and such stimulus-related characteristics on the other hand. It is, for instance, conceivable that fluid intelligence plays a more important role in cognate guessing if the degree of formal overlap between the Lx stimulus and its L1, L2, ..., Ln cognates is large. Similarly, the precise contribution of crystallised resources may hypothetically vary as a function of the corpus frequency of the Lx stimuli's cognates (see e.g. Diependaele et al. 2013; Kuperman and Van Dyke 2013). A systematic investigation of the interplay between word- and participant-related characteristics would yield a more nuanced picture of the use of cross-linguistic similarities across the lifespan.

Acknowledgments: We thank Irmtraud Kaiser, Lenny Bugayong and Nuria Ristin- Kaufmann (University of Fribourg) for their assistance in collecting the data. Thanks are also due to Barbara Ruf (University of Fribourg) for recording the digit sequences in the BW-DS task and to Kristina Borgström (University of Lund) for recording the spoken Swedish words. The raw data and R code are freely available from http://dx.doi.org/10.6084/m9.figshare.936924. 
Funding: This research was supported by a Sinergia grant from the Swiss National Science Foundation (Multilingualism through the lifespan, project 130457, PI Raphael Berthele). The first author received private financial support from Dr Ambros Boner.

\section{References}

Adank, Patti \& Esther Janse. 2010. Comprehension of a novel accent by young and older listeners. Psychology and Aging 25. 736-740.

Allen, Dave. 1992. Oxford Placement Test, 2nd edn. Oxford: Oxford University Press.

Baayen, R. Harald. 2008. Analyzing linguistic data: A practical introduction to statistics using $R$. Cambridge: Cambridge University Press.

Baayen, R. Harald, Doug J. Davidson, \& Douglas M. Bates. 2008. Mixed-effects modeling with crossed random effects for subjects and items. Journal of Memory and Language 59. 390412.

Baddeley, Alan D. \& Graham J. Hitch. 1974. Working memory. In G. H. Bower (ed.), The psychology of learning and motivation: Advances in theory and research, Vol. 8, 47-89. New York: Academic Press.

Baltes, Paul B., Ursula M. Staudinger \& Ulman Lindenberger. 1999. Lifespan psychology: Theory and application to intellectual functioning. Annual Review of Psychology 50. 471-507.

Bates, Douglas M., Martin Maechler \& Ben Bolker. 2013. lme4: Linear mixed-effect models using S4 classes. R package, version 0.999999-2. Available online from http://cran.rproject.org/package $=1 m e 4$.

Berthele, Raphael. 2008. Dialekt-Standard Situationen als embryonale Mehrsprachigkeit. Erkenntnisse zum interlingual Potenzial des Provinzlerdaseins. Sociolinguistica 22. 87-107.

Berthele, Raphael. 2011. On abduction in receptive multilingualism: Evidence from cognate guessing tasks. Applied Linguistics Review 2. 191-219.

Berthele, Raphael \& Amelia Lambelet. 2009. Approche empirique de l'intercompréhension: répertoires, processus et résultats. Lidil 39. 151-162.

Brändle, Maximilian. 1986. Language teaching for the 'young-old'. Babel 21. 17-21.

Bravo, Marco A., Elfrieda H. Hiebert \& P. David Pearson. 2007. Tapping the linguistic resources of Spanish/English bilinguals: The role of cognates in science. In R. K. Wagner, A. Muse \& K. 
Tannenbaum (eds.), Vocabulary development and its implications for reading comprehension, 140-156. New York: Guilford.

Carton, Aaron S. 1971. Inferencing: A process in using and learning language. In Paul Pimsleur \& Terence Quinn (eds.), The psychology of second language learning: Papers from the Second International Congress of Applied Linguistics, Cambridge, 8-12 September 1969, 45-58. London: Cambridge University Press.

Cenoz, Jasone. 2001. The effect of linguistic distance, L2 status and age on cross-linguistic influence in third language acquisition. In Jasone Cenoz, Britta Hufeisen \& Ulrike Jessner (eds.), Cross-linguistic influence in third language acquisition: Psycholinguistic perspectives, 8-20. Clevedon: Multilingual Matters.

Conway, Andrew R. A., Michael J. Kane, Michael F. Bunting, D. Zach Hambrick, Oliver Wilhelm \& Randall W. Engle. 2005. Working memory span tasks: A methodological review and user's guide. Psychonomic Bulletin \& Review 12. 769-786.

Cowan, Nelson. 2008. What are the differences between long-term, short-term, and working memory? Progress in Brain Research 169. 323-338.

De Groot, Annette M. B. \& Rineke Keijzer. 2000. What is hard to learn is easy to forget: The roles of word concreteness, cognate status, and word frequency in foreign-language vocabulary learning and forgetting. Language Learning 50. 1-56.

Delsing, Lars-Olof \& Katarina Lundin Åkesson. 2005. Håller språket ihop Norden? En forskningsrapport om ungdomars förståelse av danska, svenska och norska [Does language hold the Nordic countries together? A research report on the comprehension of Danish, Swedish and Norwegian by youngsters] (TemaNord 573). Copenhagen: Nordiska ministerrådet.

Diependaele, Kevin, Kristin Lemhöfer \& Marc Brysbaert. 2013. The word frequency effect in firstand second-language word recognition: A lexical entrenchment account. Quarterly Journal of Experimental Psychology 66. 843-863.

Dressler, Cheryl, Maria S. Carlo, Catherine E. Snow, Diane August \& Claire E. White. 2011. Spanish-speaking students' use of cognate knowledge to infer the meaning of English words. Bilingualism: Language and Cognition 14. 243-255. 
Engle, Randall W., Stephen W. Tuholski, James E. Laughlin \& Andrew R. A. Conway. A. 1999. Working memory, short-term memory, and general fluid intelligence: A latent-variable approach. Journal of Experimental Psychology: General 128. 309-331.

Gathercole, Susan E. 1999. Cognitive approaches to the development of short-term memory. Trends in Cognitive Sciences 3. 410-419.

Gelman, Andrew \& Hal Stern. 2006. The difference between "significant" and "not significant" is not itself statistically significant. The American Statistician 60. 328-331.

Gooskens, Charlotte, Sebastian Kürschner \& Renée van Bezooijen. 2011. Intelligibility of Standard German and Low German to speakers of Dutch. Dialectologia Special issue, II. 35-63.

Gordon-Salant, Sandra. 2005. Hearing loss and aging: New research findings and clinical implications. Journal of Rehabilitation Research \& Development 42, Supplement 2. 9-24.

Haastrup, Kirsten. 1991. Lexical inferencing procedures or talking about words: Receptive procedures in foreign language learning with special reference to English. Tübingen: Gunter Narr.

Haugen, Einar. 1966. Semicommunication: The language gap in Scandinavia. Sociological Inquiry 36. 280-297.

Ház, Éva. 2005. Deutsche und Niederländer. Untersuchungen zur Möglichkeit einer unmittelbaren Verständigung. Hamburg: Dr. Kovač.

Jaeger, T. Florian. 2008. Categorical data analysis: Away from ANOVAs (transformation or not) and towards logit mixed models. Journal of Memory and Language 59. 434-446.

Jaeger, T. Florian, Peter Graff, William Croft \& Daniel Pontillo. 2011. Mixed effect models for genetic and areal dependencies in linguistic typology. Linguistic Typology 15. 281-320.

Jarvis, Scott \& Aneta Pavlenko. 2008. Crosslinguistic influence in language and cognition. New York: Routledge.

Jensen, John B. 1989. On the mutual intelligibility of Spanish and Portuguese. Hispania 72. 848852.

Krakenberger, Etna Rosa. 2014. 50+L2, una formula per mantenersi attivi dopo il pensionamento? Bulletin Vals-Asla 99. 115-130. 
Kray, Jutta \& Ulman Lindenberger. 2007. Fluide Intelligenz. In Jochen Brandstädter \& Ulman Lindenberger (eds), Entwicklungspsychology der Lebensspanne, 194-220. Stuttgart: W. Kohlhammer.

Kuperman, Victor \& Julia A. Van Dyke. 2013. Reassessing word frequency as a determinant of word recognition for skilled and unskilled readers. Journal of Experimental Psychology: Human Perception and Performance 39. 802-823.

Kürschner, Sebastian, Charlotte Gooskens \& Renée van Bezooijen. 2008. Linguistic determinants of the intelligibility of Swedish words among Danes. International Journal of Humanities and Arts Computing 2. 83-100.

Lotto, Lorella \& Annette M. B. de Groot. 1998. Effects of learning method and word type on acquiring vocabulary in an unfamiliar language. Language Learning 48. 31-69.

Lubliner, Shira \& Elfrieda H. Hiebert. 2011. An analysis of English-Spanish cognates as a source of general academic language. Bilingual Research Journal 34. 76-93.

Martin, Katherine I. \& Nick C. Ellis. 2012. The roles of phonological short-term memory and working memory in L2 grammar and vocabulary learning. Studies in Second Language Acquisition 34. 379-413.

Meißner, Franz-Joseph. 1999. Das mentale Lexikon aus der Sicht der Mehrsprachigkeitsdidaktik. Grenzgänge 6. 62-80.

Möller, Robert. 2010. Wann sind Kognaten erkennbar? Ähnlichkeit und synchrone Transparenz von Kognatbeziehungen in der germanischen Interkomprehension. Linguistik online 46. 79-101.

Möller, Robert \& Ludger Zeevaert. 2010. „Da denke ich spontan an Tafel“: Zur Worterkennung in verwandten germanischen Sprachen. Zeitschrift für Fremdsprachenforschung 21. 217-248.

Muñoz, Carmen (ed.). 2006. Age and the rate of foreign language learning. Clevedon: Multilingual Matters.

Nieuwenhuis, Sander, Birte U. Forstman \& Eric-Jan Wagenmakers. 2011. Erroneous analyses of interactions in neuroscience: A problem of significance. Nature Neuroscience 14. 1105-1107.

Odlin, Terence. 1989. Language transfer: Cross-linguistic influences in language learning. Cambridge: Cambridge University Press. 
Park, Denise C. \& Doris Payer. 2006. Working memory across the adult lifespan. In Ellen Bialystok \& Fergus I. M. Craik (eds), Lifespan cognition. Mechanisms of change, 128-142. New York: Oxford University Press.

Ramscar, Michael, Peter Hendrix, Cyrus Shaoul, Petar Milin \& R. Harald Baayen. 2014. The myth of cognitive decline: Non-linear dynamics of lifelong learning. Topics in Cognitive Science 6. $5-42$.

Raven, John C. 1962. Advanced progressive matrices, set II. London: H. K. Lewis.

R Core Team. 2013. R: A language and environment for statistical computing. Software, version 3.0.2. Available online from http://www.r-project.org/.

Ringbom, Håkan. 1987. The role of the first language in foreign language learning. Clevedon: Multilingual Matters.

Ringbom, Håkan. 1992. On L1 transfer in L2 comprehension and L2 production. Language Learning 42. 85-112.

Ringbom, Håkan. 2007. Cross-linguistic similarity in foreign language learning. Clevedon: Multilingual Matters.

Rubin, Joan. 1975. What the "good language learner" can teach us. TESOL Quarterly 9. 41-51.

Salthouse, Timothy A. 2006. Aging of thought. In Ellen Bialystok \& Fergus I. M. Craik (eds), Lifespan cognition. Mechanisms of change, 274-284. New York: Oxford University Press.

Schielzeth, Holger \& Wolfgang Forstmeier. 2009. Conclusions beyond support: Overconfident estimates in mixed models. Behavioral Ecology 20. 416-420.

Schmidt, K.-H. \& P. Metzler 1992. Wortschatztest (WST). Weinheim: Beltz Test.

Schüppert, Anja, Nanna Haug Hilton \& Charlotte Gooskens. Forthcoming. Swedish is beautiful, Danish is ugly: Investigating the role of intelligibility for language attitudes. Accepted for publication in Linguistics.

Shiotsu, Toshihiko \& Cyril J. Weir. 2007. The relative significance of syntactic knowledge and vocabulary breadth in the prediction of reading comprehension test performance. Language Testing 24. 99-128. 
Singer, Tania, Paul Verhaeghen, Paolo Ghisletta, Ulman Lindenberger \& Paul B. Baltes. 2003. The fate of cognition in very old age: Six-year longitudinal findings in the Berlin Aging Study (BASE). Psychology and Aging 18. 318-331.

Singleton, David \& Lisa Ryan. 2004. Language acquisition: The age factor, 2nd edn. Clevedon: Multilingual Matters.

Stegmann, Tilbert D. \& Horst G. Klein. 1999. EuroComRom - Die sieben Siebe. Romanische Sprachen sofort lesen können. Aachen: Shaker Verlag.

Swarte, Femke, Anja Schüppert \& Charlotte Gooskens. 2013. Do speakers of Dutch use their knowledge of German while processing written Danish words? Linguistics in the Netherlands 30. $146-159$.

Teleman, Ulf. 1981. Om förståelse i allmänhet och om förståelse via grannspråken i synnerhet. Referat och kommentar till diskussionen i sektionen Den lexikala-semantiska komponenten i den nordiska hörförståelsen [On comprehension in general and on comprehension via neighbouring languages in specific. Summary of and commentary on the discussion in the panel on the lexico-semantic component in Nordic listening comprehension]. In ClaesChristian Elert (ed.), Internordisk språkförståelse. Föredrag och diskussioner vid ett symposium på Rungstegaard utanför Köpenhamn den 24-26 mars 1980, 102-120. Umeå: Umeå University.

Tewes, Uwe. 1991. HAWIE-R. Hamburg-Wechsler Intelligenztest für Erwachsene, Revision 1991: Handbuch und Testanweisungen. Bern: Hans Huber.

Van Bezooijen, Renée, Charlotte Gooskens \& Sebastian Kürschner. 2012. Deens is makkelijker voor Friezen dan voor Nederlanders - feit of fabel? [Danish is easier for Frisians than for Dutch people - truth or tale?]. In Piter Boersma, Goffe T. Jensma \& Reinier Salverda (eds.), Philologia Frisica anno 2008. Lêzings fan it achttjinde Frysk Filologekongres fan de Fryske Akademy op 10, 11 en 12 desimber 2008, 286-298. Leeuwarden: Afûk/Fryske Akademy.

Van Heuven, Vincent J. 2008. Making sense of strange sounds: (Mutual) intelligibility of related language varieties. A review. International Journal of Humanities and Arts Computing 2. 3962.

Verhaeghen, Paul. 2003. Aging and vocabulary scores: A meta-analysis. Psychology and Aging 18. $332-339$. 
Welford, Alan T. 1958. Ageing and human skill. London: Oxford University Press.

Wieling, Martijn, John Nerbonne \& R. Harald Baayen. 2011. Quantitative social dialectology: Explaining linguistic variation geographically and socially. PLoS ONE 6. e23613.

Wood, Simon N. 2014. mgev: Mixed GAM computation vehicle with GCV/AIC/REML smoothness estimation. R package, version 1.7-28. Available online from http://cran.rproject.org/package $=\mathrm{mgcv}$.

Zuur, Alain F., Elena N. Ieno, Neil J. Walker, Anatoly A. Saveliev \& Graham M. Smith. 2009. Mixed effects models and extensions in ecology with R. New York: Springer.

\section{Appendix A: Stimuli used in the cognate guessing task}

\section{Written stimuli}

Written stimuli used in the Swedish cognate guessing task with their model translations in English and their German, English and French translation-equivalent cognates.

\begin{tabular}{|c|c|c|c|c|}
\hline Stimulus & Translation & German & English & French \\
\hline alltid & always & allzeit & & \\
\hline avskaffa & to abolish & abschaffen & & \\
\hline bakgrund & background & & background & \\
\hline behärska & to master & beherrschen & & \\
\hline borgmästare & mayor & Bürgermeister & & \\
\hline byrå & bureau & Büro & bureau & bureau \\
\hline bäbis $^{8}$ & baby & Baby & baby & bébé \\
\hline cyckel $^{9}$ & (bi)cycle & Zyklus & cycle & cycle \\
\hline fiende & enemy & Feind & & \\
\hline fåtölj & fauteuil & Fauteuil & fauteuil & fauteuil \\
\hline försiktig & careful & vorsichtig & & \\
\hline förutsättning & requirement & Voraussetzung & & \\
\hline full & full & voll & full & \\
\hline hård & hard & hart & hard & \\
\hline kanel & cinnamon & & & cannelle \\
\hline kejsar & emperor & Kaiser & & \\
\hline kniv & knife & & knife & \\
\hline kung & king & König & king & \\
\hline 8 Bäbis is actu & common missp & bebis. This misspel & is wholly incon & al for our purposes. \\
\hline 9 A misspellir & ykel (which in & ronounced as thoug & were written $c y$ & gain, this misspelling is \\
\hline
\end{tabular}




\begin{tabular}{|c|c|c|c|c|}
\hline Stimulus & Translation & German & English & French \\
\hline kyrka & church & Kirche & church & \\
\hline kyssa & to kiss & küssen & kiss & \\
\hline löpa & to run & laufen & & \\
\hline mjölk & milk & Milch & milk & \\
\hline möjlig & possible & möglich & & \\
\hline rytmisk & rhythmic & rhythmisch & rhythmic & rythmique \\
\hline rådhus & town hall & Rathaus & & \\
\hline saliv & saliva & & saliva & salive \\
\hline skola & school & Schule & school & \\
\hline skrubba & to scrub & schrubben & scrub & \\
\hline skyskrapa & skyscraper & & skyscraper & \\
\hline sitta & to sit & sitzen & sit & \\
\hline skön & beautiful & schön & & \\
\hline spegel & mirror & Spiegel & & \\
\hline språk & language & Sprache & & \\
\hline stjärn & star & Stern & star & (star) \\
\hline söka & to search & suchen & seek & \\
\hline torsdag & Thursday & Donnerstag & Thursday & \\
\hline tunga & tongue & Zunge & tongue & \\
\hline tvivla & to doubt & zweifeln & & \\
\hline tårta & cake & Torte & $\operatorname{tart}$ & tarte \\
\hline varm & warm & warm & warm & \\
\hline viktig & important & wichtig & & \\
\hline värld & world & Welt & world & \\
\hline ytterst & extreme(ly) & äusserst & & \\
\hline öppna & to open & öffnen & open & \\
\hline översätta & to translate & übersetzen & & \\
\hline barn & child & (profile word) & & \\
\hline häst & horse & (profile word) & & \\
\hline leka & to play & (profile word) & & \\
\hline mycket & very; much & (profile word) & & \\
\hline städa & to clean & (profile word) & & \\
\hline
\end{tabular}




\section{Spoken stimuli}

Spoken stimuli used in the Swedish cognate guessing task with their model translations in English and their German, English and French translation-equivalent cognates.

\begin{tabular}{|c|c|c|c|c|}
\hline Stimulus & Translation & German & English & French \\
\hline bliva & to stay & bleiben & & \\
\hline blomma & flower & Blume & (bloom) & \\
\hline bränna & to burn & brennen & burn & \\
\hline butelj & bottle & & bottle & bouteille \\
\hline choklad & chocolate & Schokolade & chocolate & chocolat \\
\hline egenskap & characteristic & Eigenschaft & & \\
\hline elev & pupil & & & élève \\
\hline ensam & lonely & einsam & & \\
\hline fotboll & football & Fussball & football & football \\
\hline fråga & question; to ask & Frage; fragen & & \\
\hline fräsch & fresh & frisch & fresh & frais \\
\hline fönster & window & Fenster & & fenêtre \\
\hline försöka & to try & versuchen & & \\
\hline först & first & & first & \\
\hline försvinna & to disappear & verschwinden & & \\
\hline grupp & group & Gruppe & group & groupe \\
\hline gå & to go & gehen & go & \\
\hline hemlig & secret & heimlich & & \\
\hline ingenjör & engineer & Ingenieur & engineer & ingénieur \\
\hline intryck & impression & Eindruck & & \\
\hline is & ice & Eis & ice & \\
\hline konst & art & Kunst & & \\
\hline korruption & corruption & Korruption & corruption & corruption \\
\hline kägel & cone & Kegel & & \\
\hline kärnkraftverk & nuclear power station & Kernkraftwerk & & \\
\hline larm & noise; alarm & Lärm; Alarm & alarm & alarme \\
\hline lång & long & lang & long & long \\
\hline märkvärdig & remarkable & merkwürdig & & \\
\hline nackdel & disadvantage & Nachteil & & \\
\hline paraply & umbrella & & & parapluie \\
\hline passiv & passive & passiv & passive & passif \\
\hline potatis & potato & & potato & patate \\
\hline
\end{tabular}




\begin{tabular}{|c|c|c|c|c|}
\hline Stimulus & Translation & German & English & French \\
\hline självständig & independent & selbstständig & & \\
\hline skriva & to write & schreiben & & \\
\hline skärm & screen & Schirm & & \\
\hline smart & smart & smart & smart & \\
\hline smink & make-up & Schminke & & \\
\hline tydlig & clear & deutlich & & \\
\hline tänka & to think & denken & think & \\
\hline ursprung & origin & Ursprung & & \\
\hline växla & to change & wechseln & & \\
\hline ägg & egg & $\mathrm{Ei}$ & egg & \\
\hline äta & to eat & essen & eat & \\
\hline öst & east & Ost(en) & eat & \\
\hline överraska & to surprise & überraschen & & \\
\hline börja & to begin & (profile word) & & \\
\hline flicka & girl & (profile word) & & \\
\hline Sverige & Sweden & (profile word) & & \\
\hline tråkig & boring & (profile word) & & \\
\hline älska & to love & (profile word) & & \\
\hline
\end{tabular}

\section{Appendix B: Scoring protocol for the cognate translation task}

All translations were checked and coded binarily for their correctness. When checking the translations, we entirely disregarded capitalisation and we did not count misspelt words as wrong as long as the misspelling did not give rise to another existing word. Thus, keiser was accepted as a correct translation for the visual stimulus kejsar 'emperor', even though the correct spelling is Kaiser. The translation Grippe for the spoken stimulus [grep] (grupp, 'group'), on the other hand, was not considered an acceptable translation: even though it may well have a misspelling of the correct German translation Gruppe ('u' and 'i' lie right next to each other on the keyboard), Grippe is an existing word in German, meaning 'influenza'.

In case the translation provided did not perfectly match the model translation or a synonym, we operated along the following lines:

- If more than one translation was provided, the answer was rated as correct if one of the translations was correct. For instance, the answer denken oder trinken 'to think or to drink' for ['tعりka] (tänka, 'to think') was rated as correct. 
- Even though all nouns were presented in the singular, both (nominative) singular and plural translations were accepted, e.g. Blumen 'flowers' for ['bløma] (blomma, 'flower').

- Even though all verbs were presented in the infinitive, we accepted translations in the infinitive, imperative and simple present. Thus, sitz 'sit (imp.), but also: seat' was a correct translation of sitta 'to sit'.

- Even though all adjectives were presented in their predicative forms, attributive forms were also accepted, e.g. erste 'first (attr.)' for [fest] (först, 'first (pred.)').

- French and English translations were accepted as well.

We were, however, less forgiving as far as 'near-miss' translations were concerned. The translation Zirkel 'circle' for cy(c)kel '(bi)cycle' was therefore rated as incorrect. Likewise, hyper- and hyponyms of the correct translation were rated as incorrect: neither Kraftwerk 'power station' for ['ðæ:nkraftverk] (kärnkraftverk, 'nuclear power station') nor taschenmesser 'pocket knife' for kniv 'knife' were accepted as correct answers. Moreover, only translations belonging to the same part of speech as the model translation were accepted, i.e. the noun Rhythmus 'rhythm' was not considered an acceptable translation of the adjective rytmisk 'rhythmic'. Exceptions to this rule were cases in which, for instance, the imperative of the correct translation of a verb stimulus was identical to a related noun or the nominative plural of the correct noun was identical to a verb form as per the rules outlined above. 